\title{
Hydroxamic Acid-Based Histone Deacetylase (HDAC) Inhibitors Can Mediate Neuroprotection Independent of HDAC Inhibition
}

\author{
Sama F. Sleiman, ${ }^{1,2,3}$ David E. Olson, ${ }^{4}$ Megan W. Bourassa, ${ }^{1,2}$ Saravanan S. Karuppagounder, ${ }^{1,2}$ Yan-Ling Zhang, ${ }^{4}$ \\ Jennifer Gale, ${ }^{4}$ Florence F. Wagner, ${ }^{4}$ Manuela Basso, ${ }^{5}$ Giovanni Coppola, ${ }^{6}$ John T. Pinto, ${ }^{7}$ Edward B. Holson, ${ }^{4}$ \\ and $\odot$ Rajiv R. Ratan ${ }^{1,2}$ \\ ${ }^{1}$ Burke Medical Research Institute, White Plains, New York 10605, 2Department of Neurology and Neuroscience, Weill Medical College of Cornell \\ University, New York, New York 10021, ${ }^{3}$ Department of Natural Sciences, Lebanese American University, Byblos, Lebanon, ${ }^{4}$ Stanley Center for \\ Psychiatric Research, Broad Institute of Massachusetts Institute of Technology and Harvard, Cambridge, Massachusetts $02142,{ }^{5} \mathrm{Centre}$ for \\ Integrative Biology, University of Trento, Trento, Italy, ${ }^{6}$ Program in Neurogenetics, Department of Neurology, David Geffen School of Medicine, \\ University of California at Los Angeles, Los Angeles, California 90095, and 7Department of Biochemistry and Molecular Biology, New York Medical \\ College, Valhalla, New York 10595
}

Histone deacetylase (HDAC) inhibition improves function and extends survival in rodent models of a host of neurological conditions, including stroke, and neurodegenerative diseases. Our understanding, however, of the contribution of individual HDAC isoforms to neuronal death is limited. In this study, we used selective chemical probes to assess the individual roles of the Class I HDAC isoforms in protecting Mus musculus primary cortical neurons from oxidative death. We demonstrated that the selective HDAC8 inhibitor PCI-34051 is a potent neuroprotective agent; and by taking advantage of both pharmacological and genetic tools, we established that HDAC8 is not critically involved in PCI-34051's mechanism of action. We used BRD3811, an inactive ortholog of PCI-34051, and showed that, despite its inability to inhibit HDAC8, it exhibits robust neuroprotective properties. Furthermore, molecular deletion of HDAC8 proved insufficient to protect neurons from oxidative death, whereas both PCI-34051 and BRD3811 were able to protect neurons derived from HDAC8 knock-out mice. Finally, we designed and synthesized two new, orthogonal negative control compounds, BRD9715 and BRD8461, which lack the hydroxamic acid motif and showed that they stably penetrate cell membranes but are not neuroprotective. These results indicate that the protective effects of these hydroxamic acid-containing small molecules are likely unrelated to direct epigenetic regulation via HDAC inhibition, but rather due to their ability to bind metals. Our results suggest that hydroxamic acid-based HDAC inhibitors may mediate neuroprotection via HDAC-independent mechanisms and affirm the need for careful structure-activity relationship studies when using pharmacological approaches.

Key words: HDAC inhibitors; HDAC8; hydroxamic acids; neuroprotection; oxidative stress; PCI-34051

\section{Introduction}

Histone deacetylase inhibitors (HDACi) promote neuroprotection and improvements in function or extension of survival in

Received March 12, 2014; revised Sept. 4, 2014; accepted Sept. 8, 2014.

Author contributions: S.F.S., E.B.H., and R.R.R. designed research;S.F.S., D.E.O., M.W.B., Y.-I.Z., J.G., F.F.W., G.C., and J.T.P. performed research; D.E.O., S.S.K., M.B., and E.B.H. contributed unpublished reagents/analytic tools; S.F.S., G.C., and R.R.R. analyzed data; S.F.S., D.E.O., E.B.H., and R.R.R. wrote the paper.

This work was supported by a Dr. Miriam and Sheldon G. Adelson Medical Research Foundation Grant to R.R.R. and G.C., National Institutes of Health Grant P01 NIA AG014930, Project 1 to R.R.R., a Stanley Medical Research Institute Grant to E.B.H., and the Burke Foundation. S.F.S. was a Goldsmith Foundation fellow. We thank Dr. Eric Olson for the HDAC8-floxed mice and Fanny Lazzaro for help in synthesizing some of the compounds used.

The authors declare no competing financial interests.

Correspondence should be addressed to either of the following: Dr. Sama F. Sleiman, Department of Natural Sciences, Lebanese American University, P0 Box 36, Byblos, Lebanon, E-mail: sama.sleiman01@lau.edu.lb; or Dr. Rajiv R. Ratan, Burke Medical Research Institute, Department of Neurology and Neuroscience, Weill Medical College of Cornell University, 785 Mamaroneck Avenue, White Plains, NY 10605, E-mail: rrr2001@med.cornell.edu.

DOI:10.1523/JNEUROSCI.1010-14.2014

Copyright $\odot 2014$ the authors $\quad 0270-6474 / 14 / 3414328-10 \$ 15.00 / 0$ many CNS diseases (Kazantsev and Thompson, 2008; Sleiman et al., 2009). HDACi also modulate learning and memory (Fischer et al., 2007; Guan et al., 2009) and promote axonal regeneration (Rivieccio et al., 2009; Gaub et al., 2010). HDACi alter gene expression profiles by facilitating chromatin remodeling through the induction of histone acetylation (Gui et al., 2004; Sleiman et al., 2011). HDACi also exert their effects by promoting the acetylation of many nonhistone proteins (Choudhary et al., 2009), such as transcription factors (Ryu et al., 2003; Brochier et al., 2013) and cytoskeletal proteins (Sudo and Baas, 2010; Kim et al., 2012).

Considering the side effects of chronic use of pan HDACi, there has been growing interest in understanding the role of individual HDAC isoforms and developing isoform-selective HDACi. The HDAC superfamily includes Zn-dependent HDACs (HDAC1-11) and NAD-dependent sirtuins. Indeed, the functions of specific HDAC isoforms, including roles in memory for- 
mation and neuronal regeneration, have been studied. HDAC2 has been shown to negatively regulate memory formation by inhibiting the expression of synaptic plasticity genes (Guan et al., 2009; Gräff et al., 2012; Morris et al., 2013). Recently, HDAC2 has also been shown to suppress excitatory and enhance inhibitory synapses in the hippocampus (Hanson et al., 2013). Inhibition and deletion of HDAC6 have been shown to promote neurite outgrowth (Rivieccio et al., 2009).

As information on the roles of HDAC isoforms accumulates, our knowledge of the contribution of specific HDACs to neuronal degeneration remains limited. There is evidence that HDAC3 is neurotoxic and that it could possibly mediate GSK3 $\beta$ 's deathpromoting effects (Bardai and D'Mello, 2011; Bardai et al., 2012). Moreover, recent work suggests that wild-type huntingtin protein recruits HDAC3 to prevent the latter's toxic effect, whereas mutant huntingtin interferes with this interaction (Bardai et al., 2013). Although these results implicate HDAC3 in neuronal toxicity, a thorough analysis is still necessary to determine which HDACs are involved in neuronal survival.

In this manuscript, we use a pharmacological toolkit of HDACi to provide evidence that selective inhibition of individual Class I HDAC isoforms in cortical neurons does not promote protection against oxidative death. Furthermore, we demonstrate that the hydroxamic acid-based HDAC8 inhibitor PCI-34051 can mediate this neuroprotective effect via an HDAC-independent, but hydroxamic acid-dependent, mechanism. This conclusion is supported by results showing that BRD3811, a negative control compound derived from the structure of PCI-34051, protects neurons from oxidative stress despite lacking the ability to inhibit HDAC8. Moreover, BRD9715 and BRD8461, two negative control compounds that lack the hydroxamic acid group of PCI34051, fail to protect neurons from oxidative stress. These structure-activity relationship results suggest a model by which these two hydroxamic acid-based compounds protect neurons via metal chelation independent of their HDAC inhibition properties. Our results suggest that care and caution are required when interpreting the vast literature surrounding HDACi and suggest that combining both pharmacological and genetic studies is necessary to understand the role of HDAC inhibition in neuroprotection.

\section{Materials and Methods}

Cell culture. Immature primary cortical neurons were obtained from CD1 mice (embryonic day 15 [E15]) as previously described (Ratan et al., 1994b). The HT22 cell lines expressing either control shRNA or HDAC8 shRNA were cultured in DMEM (Invitrogen), 10\% FBS (Invitrogen), and $4 \mu \mathrm{g} / \mathrm{ml}$ puromycin (Sigma).

Cell viability. For cytotoxicity studies, immature primary cortical neurons were isolated as described above and plated at a density of $10^{5}$ cells/well in 96-well plates. The next day, cells were placed in medium containing the glutamate analog homocysteic acid (HCA $5 \mathrm{~mm}$ ). Different inhibitors of Class I HDACs (apicidin, PCI-34051, BRD3811) were added at the time of HCA treatment and were present throughout the experiment. The HDACi were prepared as $10 \mathrm{~mm}$ stock solutions and serial dilutions were used to arrive to the desired concentration. The next day, cell viability was assessed by the MTT assay (Promega) (Mosmann, 1983). The effectiveness of the MTT assays in measuring cell viability was confirmed by using the LIVE/DEAD assay (Invitrogen) and fluorescence microscopy.

Compound synthesis. PCI-34051 is commercially available. The synthesis of BRD3811 is thoroughly described in (Olson et al., 2014).

Synthesis of BRD8461. To a solution of 1-(4-methoxybenzyl)-1H-indole6-carboxylic acid (50 mg, $0.178 \mathrm{mmol}, 1.0$ equiv), 4-dimethylaminopyridine (4.3 mg, $0.036 \mathrm{mmol}, 0.2$ equiv), and $N, N$-diisopropylethylamine $(0.186 \mathrm{ml}$, $1.07 \mathrm{mmol}, 6$ equiv) in DMF ( $1.8 \mathrm{ml})$ was added $\mathrm{EDCI} \cdot \mathrm{HCl}(68 \mathrm{mg}, 0.355$ mmol, 2 equiv). The resulting mixture was stirred for $10 \mathrm{~min}$ before the addition of propylamine $(0.044 \mathrm{ml}, 0.533 \mathrm{mmol}, 3$ equiv). The reaction was heated at $45^{\circ} \mathrm{C}$ overnight and then diluted in saturated $\mathrm{NH}_{4} \mathrm{Cl}_{(\mathrm{aq})}(50$ $\mathrm{ml})$. The product was extracted with EtOAc $(3 \times 50 \mathrm{ml})$. The organic extracts were dried over $\mathrm{MgSO}_{4}$ and concentrated under reduced pressure. The resulting residue was purified using preparatory HPLC to afford a white solid $(0.6 \mathrm{mg}, 0.186 \mu \mathrm{mol}, 1 \%)$ in $>95 \%$ purity (as determined by LCMS, ESI ${ }^{+}$MS: $\left.m / z: 323.6[\mathrm{M}+\mathrm{H}]^{+}\right) .{ }^{1} \mathrm{H}$ NMR $(400$ $\left.\mathrm{MHz}, \mathrm{CD}_{3} \mathrm{OD}\right): \delta 7.93(\mathrm{~s}, 1 \mathrm{H}), 7.61(\mathrm{~d}, 1 \mathrm{H}, J=8.3), 7.52(\mathrm{~d}, 1 \mathrm{H}, J=8.5)$, $7.40(\mathrm{~d}, 1 \mathrm{H}, J=3.1), 7.12(\mathrm{~d}, 2 \mathrm{H}, J=8.5), 6.85(\mathrm{~d}, 2 \mathrm{H}, J=8.6), 6.54(\mathrm{~d}$, $1 \mathrm{H}, J=2.8), 5.37(\mathrm{~s}, 2 \mathrm{H}), 3.74(\mathrm{~s}, 3 \mathrm{H}), 3.35(\mathrm{t}, 2 \mathrm{H}, J=7.1), 1.70-1.60(\mathrm{~m}$, $2 \mathrm{H}), 0.98(\mathrm{t}, 3 \mathrm{H}, J=7.4) \mathrm{ppm}$.

Synthesis of BRD 9715. Lithium hydroxide $(668 \mathrm{mg}, 27.9 \mathrm{mmol}, 20$ equiv) was added to a solution of methyl 1-(4-methoxybenzyl)-1Hindole-6-carboxylate (412 $\mathrm{mg}, 1.40 \mathrm{mmol}, 1.0$ equiv) in $27.9 \mathrm{ml}$ of $2: 1$ $\mathrm{THF} / \mathrm{H}_{2} \mathrm{O}$. The resulting mixture was heated to $100^{\circ} \mathrm{C}$, stirred overnight, concentrated under reduced pressure, and diluted in saturated $\mathrm{NH}_{4} \mathrm{Cl}_{(\mathrm{aq})}(100 \mathrm{ml})$. The product was extracted with EtOAc $(3 \times 50 \mathrm{ml})$. The organic extracts were dried over $\mathrm{MgSO}_{4}$ and concentrated under reduced pressure. The resulting residue was purified using flash chromatography (gradient elution 100\% hexanes $\rightarrow 1: 1$ hexanes:EtOAc) to afford a white solid (154 mg, $0.547 \mathrm{mmol}, 39 \%$ ) in $>95 \%$ purity (as determined by LCMS, ESI ${ }^{+}$MS: $\left.m / z: 282.8[\mathrm{M}+\mathrm{H}]^{+}\right) .{ }^{1} \mathrm{H}$ NMR $(400$ $\mathrm{MHz}, \mathrm{CDCl}_{3}$ ): $\delta 11.68$ (br s, $\left.1 \mathrm{H}\right), 8.19(\mathrm{~s}, 1 \mathrm{H}), 7.87(\mathrm{~d}, 1 \mathrm{H}, J=8.4), 7.68$ $(\mathrm{d}, 1 \mathrm{H}, J=8.4), 7.28(\mathrm{~d}, 1 \mathrm{H}, J=3.1), 7.10(\mathrm{~d}, 2 \mathrm{H}, J=8.6), 6.85(\mathrm{~d}, 2 \mathrm{H}$, $J=8.6), 6.59(\mathrm{~d}, 1 \mathrm{H}, J=3.1), 5.33(\mathrm{~s}, 2 \mathrm{H}), 3.77(\mathrm{~s}, 3 \mathrm{H}) \mathrm{ppm}$.

HDAC inhibition assay (microfluidic lab-on-a-chip assay). All HDACs were purchased from BPS Bioscience. The substrates Broad Substrate A and Broad Substrate B were synthesized in house but can be purchased from PerkinElmer (product \#CLS960006 and \#CLS960007, respectively). All other reagents were purchased from Sigma. Caliper EZ reader II system was used to collect all data. Compounds were tested in duplicate in a 12-point dose curve with threefold serial dilution starting from $33.33 \mu \mathrm{M}$. Purified HDACs were incubated with $2 \mu \mathrm{M}$ carboxyfluorescein (FAM)labeled acetylated or trifluoroacetylated peptide substrate (Broad Substrate $\mathrm{A}$ and $\mathrm{B}$, respectively) and test compound for $60 \mathrm{~min}$ at room temperature, in HDAC assay buffer that contained $50 \mathrm{~mm}$ HEPES, $\mathrm{pH}$ 7.4, $100 \mathrm{~mm} \mathrm{KCl}, 0.01 \% \mathrm{BSA}$, and $0.001 \%$ Tween 20 . Reactions were terminated by the addition of the known pan HDAC inhibitor LBH-589 (panobinostat) with a final concentration of $1.5 \mu \mathrm{M}$. Substrate and product were separated electrophoretically, and fluorescence intensity in the substrate and product peaks was determined and analyzed by Labchip EZ Reader. The percentage inhibition was plotted against the compound concentration, and the $\mathrm{IC}_{50}$ values were automatically fitted by Genedata Screener software using 4-parameter logistic dose-response model.

Glutathione measurement. Concentrations of reduced glutathione were measured using HPLC (PerkinElmer) equipped with an 8-channel colorimetric array detector (ESA) as previously described (Lange et al., 2008). Briefly, cells were lysed in $5 \%(\mathrm{w} / \mathrm{v})$ metaphosphoric acid and centrifuged at $14,000 \mathrm{rpm}$ for $10 \mathrm{~min}$ to precipitate proteins. Cell-pellet precipitates were saved for protein determinations. Glutathione concentrations of the supernatant fractions were determined by injecting $5 \mu$ aliquots onto an Ultrasphere $5 \mathrm{u}, 4.6 \times 250 \mathrm{~mm}, \mathrm{C} 18$ column (Beckman Coulter), and eluting with a mobile phase of $50 \mathrm{mM} \mathrm{NaH}_{2} \mathrm{PO}_{4}, 0.05 \mathrm{~mm}$ octane sulfonic acid, $1.5 \%$ acetonitrile, $\mathrm{pH} 2.62$, at a flow rate of $1 \mathrm{ml} / \mathrm{min}$. Peak areas were analyzed using software from ESA.

Immunoblot analysis. To determine acetyl tubulin protein levels, total cell proteins were prepared by lysing cells in $1 \%$ Triton buffer $(25 \mathrm{~mm}$ Tris $\mathrm{pH}$ 7.4, $100 \mathrm{~mm} \mathrm{NaCl}, 1 \mathrm{~mm}$ EGTA, 1\% Triton X-100, protease inhibitors, $2.5 \mathrm{~mm}$ sodium orthovanadate). To determine acetyl histone $\mathrm{H} 4$ protein levels, total cell proteins were prepared by lysing the cells in RIPA-B (1\% Triton X-100, 1\% SDS, 50 mm Tris-Cl, pH 7.4, $500 \mathrm{~mm}$ $\mathrm{NaCl}$, and $1 \mathrm{~mm}$ EDTA) followed by benzonase nuclease digestion for 15 min. To determine HDAC8 protein levels, nuclear and cytoplasmic proteins were obtained using NE-PER Nuclear and Cytoplasmic Extraction Reagents (Pierce Biotechnology) in the presence of protease inhibitors, the proteasome inhibitor MG-132, and phosphatase inhibitors according to the manufacturer's protocol. To determine acetylated smc-3 protein levels, total cell proteins were prepared by lysing cells first in buffer A (10 
A

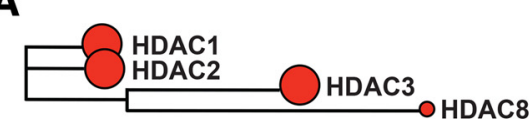

B
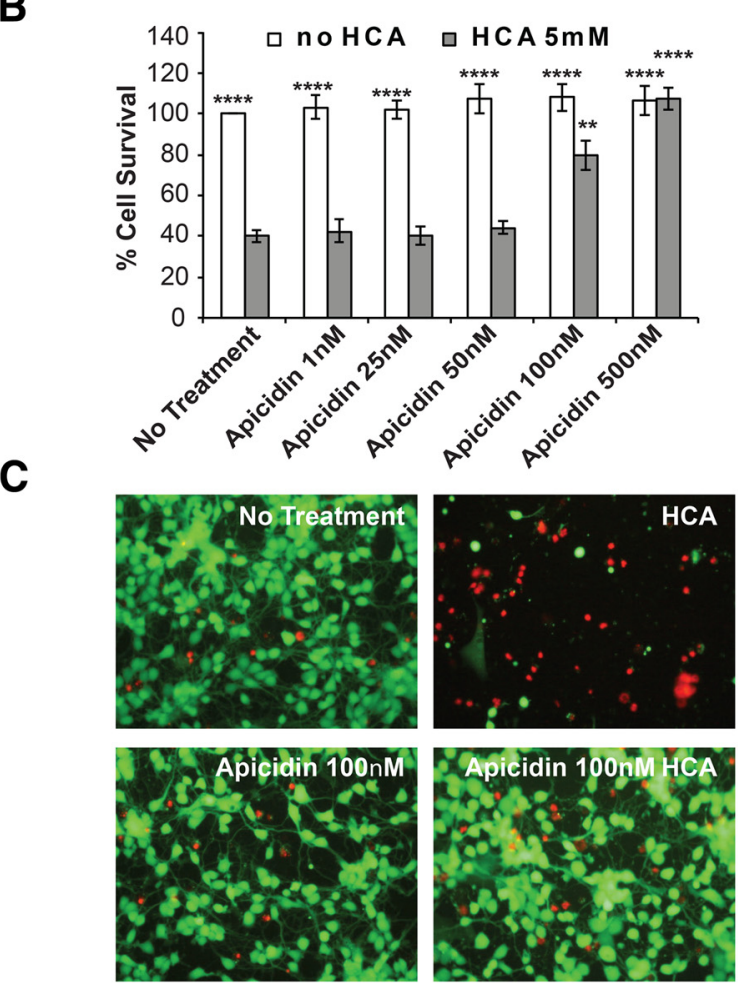

D

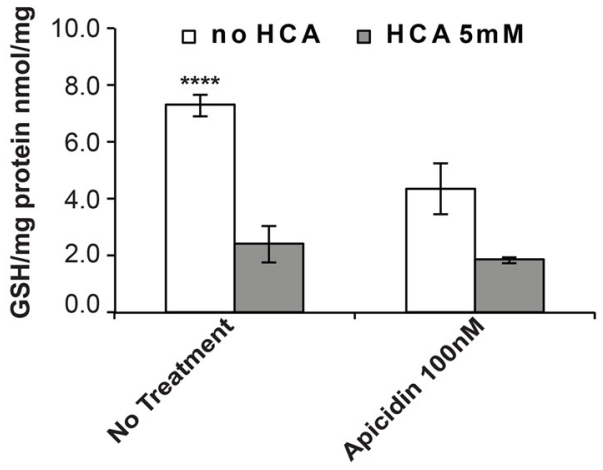

Figure 1. The Class I HDAC inhibitor apicidin potently protects primary immature cortical neurons from glutathione depletion-induced death. $A$, Chemical phylogeny tree with respective $\mathrm{K}_{\mathrm{i}}$ s. Larger red circles represent lower $\mathrm{K}_{\mathrm{i}} \mathrm{s}$. $\boldsymbol{B}$, Apicidin protects primary cortical neurons from glutathione depletion-induced death in a concentration-dependent manner. Cell death was measured $24 \mathrm{~h}$ after treatment with the glutamate analog HCA with or without the Class I HDAC inhibitor apicidin by monitoring MTT reduction. Significant protection compared with HCAtreated cells: ${ }^{* *} p<0.01 ;{ }^{* * *} p<0.0001$. C, Apicidin protects primary cortical neurons from glutathione depletion-induced death as monitored by calcein fluorescence (green fluorescence, to detect live cells) and ethidium homodimer staining (red fluorescence, to detect dead cells). D, Apicidin protects primary cortical neurons from oxidative death without increasing glutathione levels. Total reduced glutathione was measured by HPLC. Apicidin reduced glutathione levels in vehicle-treated cortical neurons but does not affect the ability of HCA to deplete reduced glutathione. Significant glutathione levels compared with HCA-treated cells: ${ }^{* * * *} p<0.0001$.

mM HEPES, pH 7.9, $10 \mathrm{~mm} \mathrm{KCl,} 1.5 \mathrm{~mm} \mathrm{MgCl}_{2}, 0.34 \mathrm{M}$ sucrose, $10 \%$ glycerol, $0.1 \%$ Triton X-100, $1 \mathrm{~mm}$ DTT, protease inhibitors, PMSF, MG132, sodium orthovanadate). Next, nuclear proteins were extracted in buffer B ( $3 \mathrm{~mm}$ EDTA, $0.2 \mathrm{~mm}$ EGTA, $0.3 \mathrm{M} \mathrm{NaCl}, 1 \mathrm{~mm}$ DTT, protease inhibitors, PMSF, MG132, sodium orthovanadate). Samples were boiled in Laemmli buffer and electrophoresed under reducing conditions on NuPAGE Novex $4 \%-12 \%$ Bis-Tris Gel polyacrylamide gels (Invitrogen). Proteins were transferred to a nitrocellulose membrane (Bio-Rad) by electroblotting. Nonspecific binding was inhibited by incubation in Odyssey blocking buffer (LI-COR Biosciences). Antibodies against acetylated tubulin (clone 6-11B-1; Sigma), tubulin (Sigma), histone H4 (05-858R, Millipore), acetyl histone H4 (06-866, Millipore), SMC-3 (A300-060A, Bethyl Laboratories), acetyl SMC-3 (PD040, MBL), and $\beta$-actin (AC-74; Sigma-Aldrich) were diluted 1:1000, 1:1000; 1:1000, $1: 2000,1: 2000,1: 1000$, and 1:10,000, respectively, in odyssey blocking buffer, and the membranes were incubated overnight at $4^{\circ} \mathrm{C}$. Fluorophore-conjugated Odyssey IRDye-680 or IRDye-800 secondary antibody (LI-COR Biosciences) was used at 1:10,000 dilution followed by incubation for $1 \mathrm{~h}$ at room temperature. Finally, proteins were detected using an Odyssey infrared imaging system (LI-COR Biosciences).

Immunoprecipitation. The $200 \mu \mathrm{g}$ of nuclear proteins was diluted in 50 $\mathrm{mm}$ Tris- $\mathrm{HCl}, \mathrm{pH} 7.4$, in the presence of protease inhibitors (Sigma), PMSF, MG132, and sodium orthovanadate and precleared with beads (Santa Cruz Biotechnology) for $30 \mathrm{~min}$ and immunoprecipitated with 1 $\mu \mathrm{g}$ of SMC-3 antibody overnight.

HDAC8 shRNA knockdown. HT22 hippocampal neuron cells were transfected with MISSION HDAC8 (NM_027382.3) validated shRNA plasmid DNA (Sigma-Aldrich) using Lipofectamine 2000 (Invitrogen) in accordance with the manufacturer's protocol. Stably transfected HT22 neurons were selected over several weeks by the addition of puromycin (4 $\mu \mathrm{g} / \mathrm{ml}$ ) to the culture medium. Puromycin-resistant clones were pooled to avoid confounds introduced by clonal selection, and HDAC8 knockdown was verified by Western blotting. Three sequences were respectively used and analyzed. In addition, MISSION Non-Target shRNA Control Vector (SHC002) (Sigma-Aldrich) was used as a negative control. This vector contains an shRNA insert that does not target human and mouse genes. In addition, cells were treated with 5 mм HCA overnight in the presence of the HDAC8 inhibitor PCI-34051 and viability was assessed using the MTT assay.

HDAC8 conditional knock-out. HDAC8-floxed mice were a kind gift from Dr. Eric Olson (Haberland et al., 2009). Heterozygous females were mated with males carrying tamoxifen-inducible Cre-mediated recombination system driven by the chicken $\beta$ actin promoter/enhancer coupled with the cytomegalovirus immediate-early enhancer. Tamoxifen (3 $\mathrm{mg} / 40 \mathrm{~g}$ weight) was administered to the pregnant mouse when the embryos were at E13. Tamoxifen will induce Cre recombination in developing embryos of treated mothers (Hayashi and McMahon, 2002). Two days later, the pregnant mother was killed and each individual E15 embryo cortex was used to make primary cortical neurons as described above. Considering that the HDAC8 gene is located on the X chromosomes of mice, we expect that half of the male embryos to be wild-type and the other half to be HDAC8-floxed males. We genotyped each embryo for the presence of the HDAC8-floxed gene and the tamoxifeninducible Cre recombinase gene (primers: $5^{\prime}$-TCAGCCTTGGATATG CTAGCC- $3^{\prime} ; 5^{\prime}$-TTGCCAGAGTAGACCTAAGTGCT- $3^{\prime} ; 5^{\prime}$-TCCTGTT TCTAGAGCCACATCC-3'). Cultures derived from embryos having the HDAC8-floxed gene and lacking the Cre recombinase gene served as controls, and cultures derived from embryos carrying both the HDAC8floxed gene and the Cre recombinase gene served as the experimental group. HDAC8 knockdown was assessed by both real time RT-PCR (primers: 5'-GAATATGGACTAGGTTATGACTGCCCAG-3' and 5'GCTACTTTACACTTCCCGTCAATCAG-3') and Western blots.

Statistical analysis. One-way or two-way ANOVA followed by the Dunnett or Bonferroni post tests, respectively, were used to measure statistical significance. $p<0.05$ was considered to be statistically significant.

\section{Results}

The Class I HDAC inhibitor apicidin protects against oxidative death in cortical neurons

Previously, we as well as others have shown that broad-spectrum HDACi are neuroprotective in mouse models of neurodegenerative diseases, such as Huntington's disease and in stroke (Ferrante 
A<smiles>COc1ccc(Cn2ccc3ccc(C(=O)NO)cc32)cc1</smiles>

C

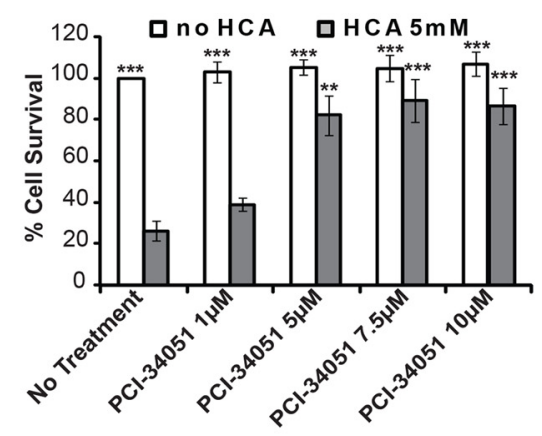

$\mathbf{E}$

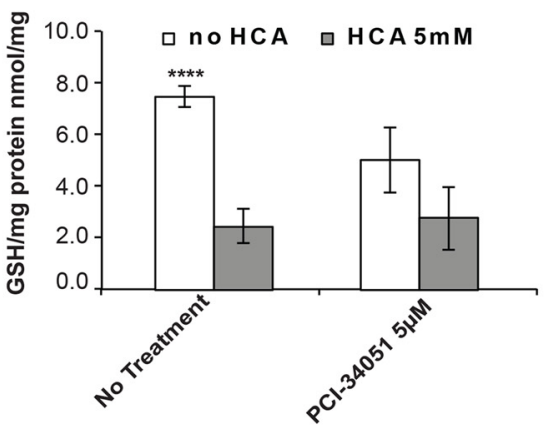

B

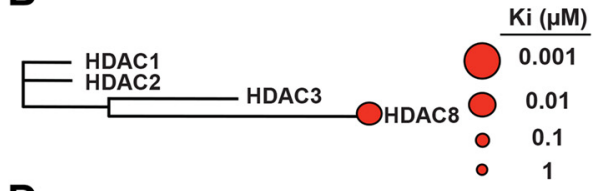

D

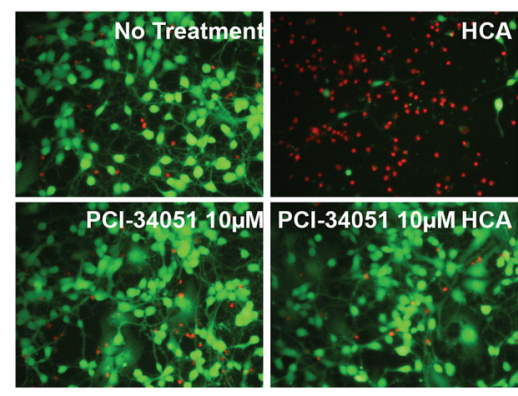

$\mathbf{F}$

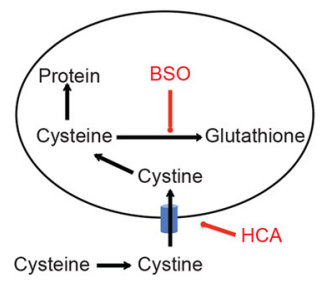

口 ПоHCA

口HCA $5 \mathrm{mM}$

BSO $200 \mu \mathrm{M}+\mathrm{HCA} 5 \mathrm{mM}$

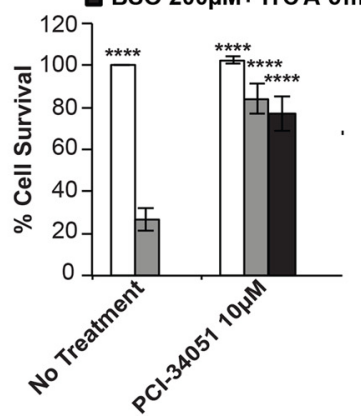

Figure 2. The $\mathrm{HDAC} 8$ inhibitor $\mathrm{PCl}-34051$ protects primary immature neurons from glutathione depletion-induced death without restoring glutathione levels. $A$, Structure of $\mathrm{PCl}-34051$. B, Chemical phylogeny tree with respective $\mathrm{K}_{\mathrm{s}}$. Larger red circles represent lower $\mathrm{K}_{\mathrm{i}} \mathrm{s}$. C, $\mathrm{PCl}-34051$ protects primary cortical neurons from glutathione depletion-induced death in a concentrationdependent manner. Cell death was measured $24 \mathrm{~h}$ after treatment with the glutamate analog HCA with or without HDAC8 inhibitor PCl-34051 by monitoring MTT reduction. Significant protection compared with HCA-treated cells: ${ }^{* *} p<0.01 ;{ }^{* * *} p<0.0001$. D, $\mathrm{PCl}-34051$ protects primary cortical neurons from glutathione depletion-induced death as monitored by calcein fluorescence (green fluorescence, to detect live cells) and ethidium homodimer staining (red fluorescence, to detect dead cells). E, PCI-34051 protects primary cortical neurons from oxidative death without increasing glutathione levels. Total reduced glutathione was measured by HPLC. PCI-34051 reduced glutathione levels in vehicle-treated cortical neurons but does not affect the ability of HCA to deplete reduced glutathione. Significant glutathione levels compared with HCA-treated cells: ${ }^{* * *} p<0.0001$. F, PCI-34051 protects primary cortical neurons from glutathione depletion-induced death independent of glutathione synthesis. Buthionine sulfoximine (BSO), an inhibitor of glutathione synthesis, did not affect PCI-34051's ability to protect neurons from oxidative death. Cell death was measured $24 \mathrm{~h}$ after treatment with the glutamate analog HCA with or without HDAC8 inhibitor PCI-34051 by monitoring MTT reduction. Significant protection compared with HCA-treated cells: ${ }^{* * *} p<0.0001$.

et al., 2003; Ryu et al., 2003; Kazantsev and Thompson, 2008; Sleiman et al., 2011). Although their neurotherapeutic potential is promising, these compounds inhibit multiple HDAC isoforms and disrupt cellular processes that depend on protein acetylation, many of which may not be involved in neuronal toxicity or death. Indeed, over the past few years, evidence has accumulated suggesting that acetylation is a modification that rivals phosphorylation in terms of scope and importance (Kouzarides, 2000; Choudhary et al., 2009). This has emphasized the urgent need for isoform-selective HDACi. Isoform-selective HDACi may alter pathways specifically involved in neuronal death, and therefore, could provide a wider therapeutic value compared with the compounds currently available.

The need for such inhibitors has heightened interest in understanding the functions of the different HDAC isoforms, in part, by synthesizing isoformselective HDACi. Considering the central role that oxidative stress plays in neuronal death due to both chronic and acute insults to the brain, we have been interested in studying the mechanisms underlying HDAC inhibitor-mediated neuroprotection from oxidative death. Our goals in this study were as follows: (1) to use a systematic approach using isoform-selective HDACi to identify the HDAC isoform(s) involved in oxidative death in cortical neurons; (2) to identify the pathways affected by the culprit HDAC(s) underlying the neuroprotection; and (3) to assess the potential of targeting specific HDACs for neuroprotection. Some evidence implicating particular HDAC isoforms, such as HDAC1 (Bardai et al., 2012), HDAC3 (Bardai et al., 2013), and HDAC6 (Rivieccio et al., 2009), has been reported.

To refine our understanding of which HDACs are relevant in oxidative stressinduced neurodegeneration, we used an established in vitro model of neuronal oxidative death. Early in their development in culture, cortical neurons exposed continuously to glutamate (or the glutamate analog homocysteic acid [HCA]) succumb through a mechanism dependent on competitive inhibition of cystine transport (Ratan et al., 1994b). Reduced intracellular cyst(e)ine leads to depletion of the antioxidant glutathione. Cell death attributable to glutathione depletion has features of apoptosis and can be completely prevented by classical antioxidants (Ratan et al., 1994a). We have previously shown that nonselective HDACi, such as trichostatin A (TSA), suberoylanilide hydroxamic acid, or Scriptaid protect neurons against glutathione depletioninduced neuronal death (Ryu et al., 2003; Langley et al., 2008; Sleiman et al., 2011). Considering that HDAC6, a Class IIb HDAC, has been shown to play a role in neuroprotection (Rivieccio et al., 2009), we focused on Class I HDACs. To determine whether the Class I HDACs are involved in this neuroprotection, we treated primary cortical neurons with HCA (a glutamate analog, $5 \mathrm{~mm}$ ) alone or with varying concentrations of apicidin, an HDAC inhibitor specific for the Class I isoforms (Bradner et al., 2010) (Fig. 1A), and then assessed cell death quantitatively and qualitatively using MTT reduction and LIVE/DEAD staining, respectively. We observed that apicidin potently protects neurons 
from oxidative stress-induced neuronal death (Fig. $1 B, C$ ). The protective effect of Apicidin occurred without restoration of glutathione levels in the neurons, suggesting that apicidin protects neurons downstream of glutathione depletion, and not by preventing the ability of glutamate or its analogs (HCA) to inhibit cystine uptake (Fig. 1D).

\section{The HDAC8 selective inhibitor PCI-34051 protects against oxidative death in cortical neurons}

To further characterize the specific HDAC isoform(s) involved in mediating oxidative death in cortical neurons, we used a pharmacological approach. Using available ortho-aminoanilide inhibitors targeting HDAC1, HDAC1 + HDAC2, and HDAC3, we did not observe any protection against glutathione depletion-induced neuronal death (data not shown). We next tested an established and highly selective HDAC8 inhibitor, PCI-34051, a hydroxamic acidbased HDAC inhibitor (Fig. 2A). PCI34051 was first identified as a HDAC8 selective inhibitor with a specificity of $>200$-fold over other HDAC inhibitors in in vitro assays. It was also established that the use of PCI-34051 phenocopied the effects obtained with HDAC8 knockdown in HeLa cells, such as lack of histone acetylation, lack of tubulin acetylation, and induction of apoptosis in T-cell lymphomas (Balasubramanian et al., 2008). Moreover, like HDAC8 knockdown, PCI34051 induced smc-3 acetylation in multiple cell types (Deardorff et al., 2012; Olson et al., 2014). Biochemical assays revealed that PCI-34051 was very potent and inhibited HDAC8 with a $\mathrm{K}_{\mathrm{i}}$ in the nanomolar range (Table 1; Fig. $2 B$ ). We treated primary cortical neurons with HCA ( $5 \mathrm{~mm}$ ) alone or with varying concentrations of PCI-34051 and then assayed cell death using MTT reduction and LIVE/DEAD staining (Fig. 2C,D). We observed that treatment with PCI-34051 protects against oxidative death in cortical neurons (Fig. 2C,D), and like apicidin, does not prevent the decrease in glutathione levels resulting from HCA treatment (Fig. 2E), suggesting that PCI-34051mediated neuroprotection occurs downstream of depletion of glutathione levels. Indeed, PCI-34051 protected neurons from oxidative death even in the presence of buthionine sulfoximine, an inhibitor of gamma-glutamylcysteine synthetase (gamma-GCS), the rate-limiting step in glutathione synthesis (Fig. 2F). These findings confirm that PCI-34051 protects independently of increasing glutathione levels. Interestingly, however, considering that the apicidin concentrations required for neuroprotection were consistent with its ability to inhibit HDACs, the relatively high concentrations of PCI-34051 $(\mu \mathrm{M})$ required for the same effect were suspident Western blots.
Table 1. Comparison of HDAC inhibition constant for compounds used in this study

\begin{tabular}{llllll}
\hline HDAC & Apicidin & PCl-34051 & BRD3811 & BRD9715 & BRD8461 \\
\hline 1 & $0.0003 \pm 0.0002$ & $24.4 \pm 12.8$ & $>25$ & $>25$ & $>25$ \\
2 & $0.0009 \pm 0.0006$ & $17.8 \pm 15.4$ & $>25$ & $>25$ & $>25$ \\
3 & $0.0007 \pm 0.0006$ & $>25$ & $>25$ & $>25$ & $>25$ \\
4 & $>25$ & $>25$ & $>25$ & $>25$ & $>25$ \\
5 & $24.5 \pm 1.82$ & $>25$ & $>25$ & $>25$ & $>25$ \\
6 & $1.74 \pm 0.763$ & $7.92 \pm 5.13$ & $>25$ & $>25$ & $>25$ \\
7 & $>25$ & $>25$ & $>25$ & $>25$ & $>25$ \\
8 & $0.283 \pm 0.076$ & $0.011 \pm 0.006$ & $>25$ & $>25$ & $>25$ \\
9 & $>25$ & $>25$ & $>25$ & $>25$ & $>25$ \\
\hline
\end{tabular}

A
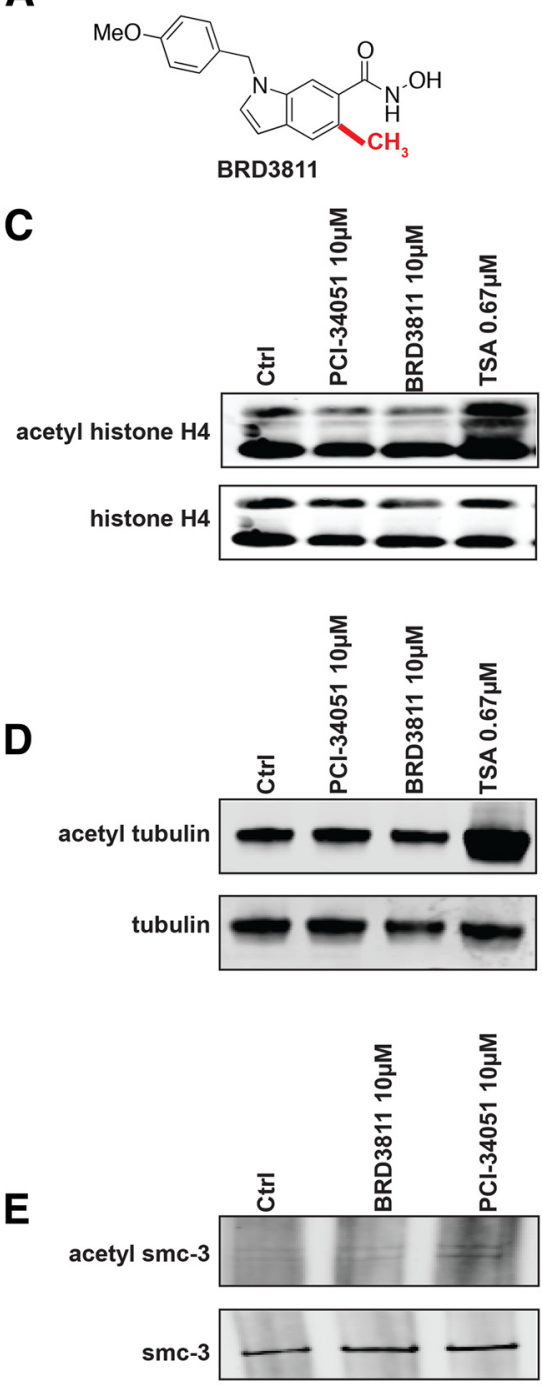

B

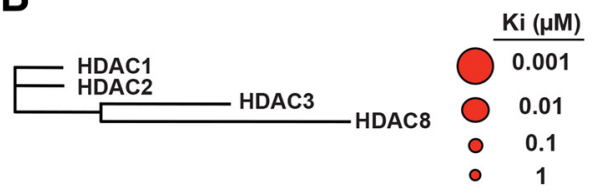

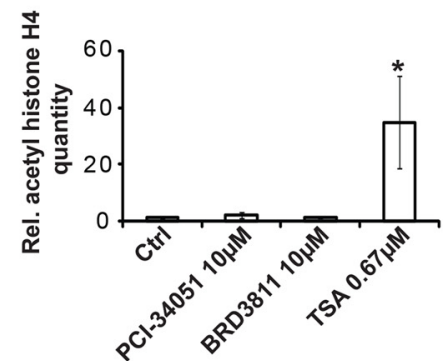
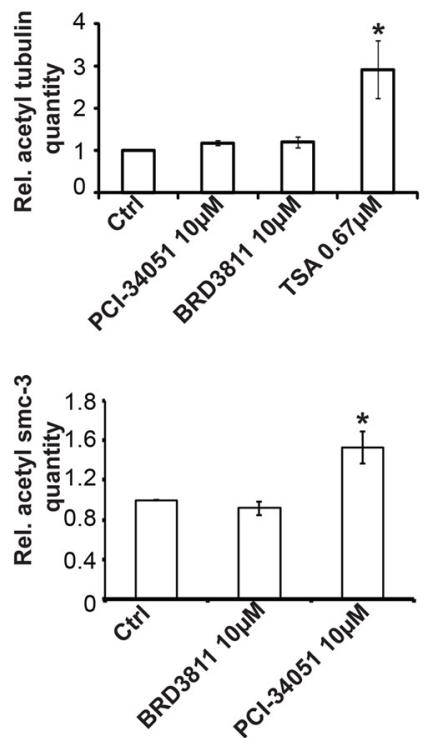

Figure 3. Validation of the PCI-34051 and BRD3811 behavior in neurons. A, Structure of BRD3811. B, Chemical phylogeny tree with respective $K_{i}$ s. Larger red circles represent lower $K_{i} s . C$, PCI-34051 and BRD3811 do not increase total histone $\mathrm{H} 4$ acetylation, whereas the broad-spectrum HDAC inhibitor TSA significantly increased total histone $\mathrm{H} 4$ acetylation. Bar graphs represent the quantification results of three independent Western blots. Significant increases in histone $\mathrm{H} 4$ acetylation compared with control: ${ }^{*} p<0.05$. D, PCI-34051 and BRD3811 do not affect tubulin acetylation, whereas TSA, known to robustly inhibit HDAC6, significantly increased tubulin acetylation. Bar graphs represent the quantification results of three independent Western blots. Significant increases in histone $\mathrm{H} 4$ acetylation compared with control: ${ }^{*} p<$ 0.05. E, PCI-34051 induces the acetylation of SMC-3, an HDAC8 target, whereas BRD3811 does not. This suggests that $\mathrm{PCl}-34051$ inhibits $\mathrm{HDAC}$, whereas BRD3811 does not. Bar graphs represent the quantification results of three indepen- 
A

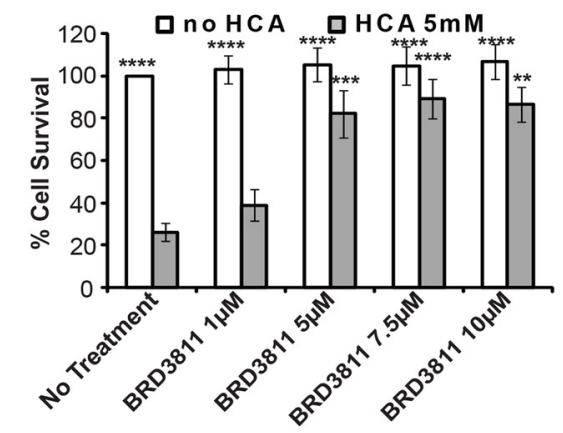

C

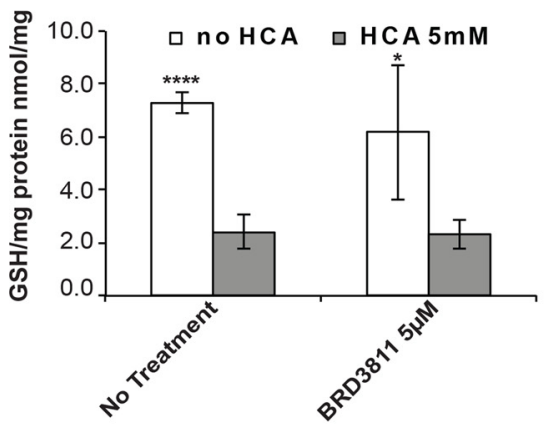

B

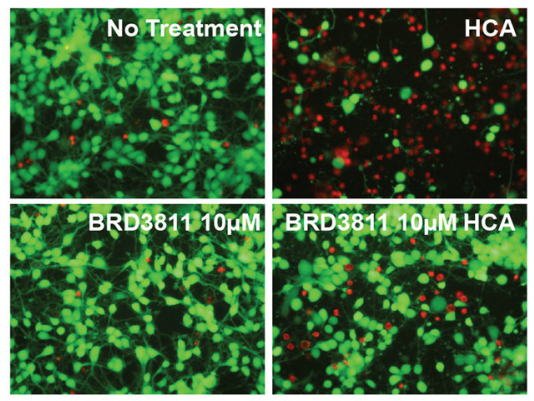

D
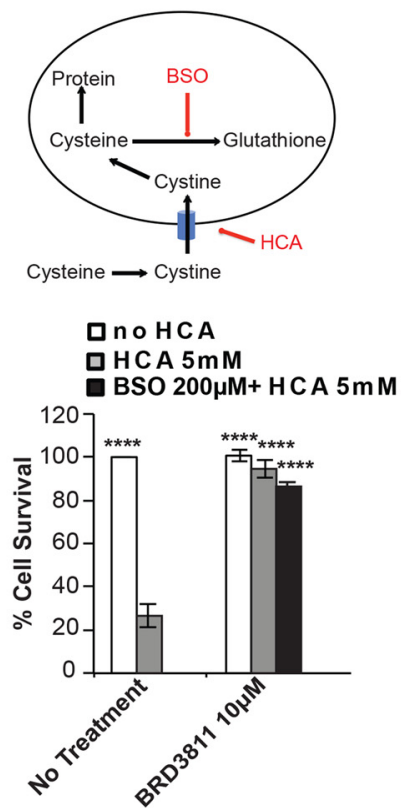

Figure 4. The newly synthesized $\mathrm{PCl}-34051$ structural analog BRD3811 protects primary immature neurons from glutathione depletion-induced death without restoring glutathione levels. $\boldsymbol{A}, \mathrm{BRD} 3811$ protects primary cortical neurons from glutathione depletion-induced death in a concentration-dependent manner. Cell death was measured $24 \mathrm{~h}$ after treatment with the glutamate analog HCA with or without BRD3811 by monitoring MTT reduction. Significant protection compared with HCA-treated cells: ${ }^{* *} p<0.01 ;{ }^{* * *} p<0.0001 ;{ }^{* * *}$. B, BRD3811 protects primary cortical neurons from glutathione depletion-induced death as monitored by calcein fluorescence (green fluorescence, to detect live cells) and ethidium homodimer staining (red fluorescence, to detect dead cells). C, BRD3811 protects primary cortical neurons from oxidative death without increasing glutathione levels. Total reduced glutathione was measured by HPLC. BRD3811 does not affect the ability of HCA to deplete reduced glutathione. Significant glutathione levels compared HCA-treated cells: ${ }^{*} p<0.05 ;{ }^{* * *} p<0.0001$. D, BRD3811 protects primary cortical neurons from glutathione depletion-induced death independent of glutathione synthesis. Buthionine sulfoximine (BSO), an inhibitor of glutathione synthesis, did not affect PCl-34051's ability to protect neurons from oxidative death. Cell death was measured $24 \mathrm{~h}$ after treatment with the glutamate analog HCA with or without BRD3811 by monitoring MTT reduction. Significant protection compared with HCA-treated cells: ${ }^{* * * *} p<0.0001$.

cious. For this reason, we further investigated the mechanism of action of PCI-34051.

\section{BRD3811, a structural analog of PCI-34051, that does not inhibit HDAC8, protects against oxidative death in cortical neurons}

To better understand the mechanism of action of PCI-34051, we reasoned that the use of an inactive ortholog of PCI-34051 that retained the zinc chelating hydroxamic acid motif would allow us to assess the specific role of HDAC8 inhibition in neuroprotection from oxidative death. We used an analog, BRD3811 (Olson et al., 2014). This compound has the same structure as PCI-34051 with the exception of an additional methyl group ortho to the hydroxamic acid (Fig. 3A). The presence of this methyl group prevents BRD3811 from accessing the tubular pocket of HDAC8 to coordinate zinc in the active site (Olson et al., 2014). Indeed, biochemical assays demonstrate that BRD3811 does not inhibit any HDAC (Table 1; Fig. 3B) (Olson et al., 2014), a result that is in stark contrast to PCI34051, which inhibits HDAC8 in the nanomolar range.

To verify in cortical neurons that PCI34051 selectively inhibits HDAC8 and BRD3811 does not, we examined the acetylation status of a number of proteins. It is well established that broad-spectrum HDACi induce acetylation of histone $\mathrm{H} 4$. Knockdown of HDAC8, on the other hand, does not induce any histone H4 acetylation (Oehme et al., 2009). As predicted, TSA significantly induced histone H4 acetylation, whereas both PCI-34051 and BRD3811 did not (Fig. 3C). Moreover, considering that many of the known HDAC6 inhibitors are hydroxamic acids and that both PCI-34051 and BRD3811 are hydroxamic acids, we next evaluated the possibility that our inhibitors affect HDAC6 to mediate neuroprotection. Tubulin is an established HDAC6 target. Inhibition of HDAC6 by selective inhibitors or by broad-spectrum inhibitors, such as TSA, enhances tubulin acetylation (Fig. 3D). As expected, both PCI-34051 and BRD3811 did not induce tubulin acetylation. Finally, to validate that PCI-34051 is a specific HDAC8 inhibitor, whereas BRD3811 does not inhibit HDAC8, we tested whether these compounds can induce the acetylation of a defined HDAC8 target, SMC-3. SMC-3, a member of the cohesin complex, is among the few in vivo validated HDAC8 target proteins (Deardorff et al., 2012). We immunoprecipitated SMC-3 from cortical neurons treated with PCI-34051 or BRD3811 and then assessed SMC-3 acetylation using an acetyl SMC-3 antibody. Only PCI-34051 induced SMC-3 acetylation, whereas BRD3811 did not (Fig. 3E). This result was also confirmed using mass spectrometry analysis of proteins acetylated by PCI-34051 treatment and not by BRD3811 (Olson et al., 2014). These results, along with microarray data (S.F.S. and R.R.R., unpublished data) demonstrating that the transcriptional responses induced by PCI-34051 and BRD3811 in neurons are highly distinct, clearly demonstrate that, even though PCI-34051 and BRD3811 have similar structures, the first is a specific HDAC8 inhibitor whereas the second is not.

To determine whether the protection from oxidative stressinduced neuronal death observed with PCI-34051 is specifically due to its ability to inhibit HDAC8, we tested whether BRD3811, the inactive ortholog of PCI-34051, could protect primary cortical neurons against oxidative death. Surprisingly, BRD3811 protected cortical neurons from glutathione depletion-induced 
neuronal death (Fig. 4A,B). Like PCI34051, BRD3811's neuroprotective effect was independent of glutathione (Fig. $4 C, D)$. Considering that the concentrations of PCI-34051 and BRD3811 required for neuroprotection were identical (5-10 $\mu \mathrm{M})$, our results suggest that a mechanism independent from HDAC8 inhibition accounts for both PCI-34051 and BRD3811's neuroprotective effects.

\section{HDAC8 knockdown does not protect cortical neurons against glutathione depletion-induced death}

To investigate the role of HDAC8 in oxidative stress-induced neuronal death directly, we reduced HDAC8 gene expression using RNA interference. We first knocked down HDAC8 in HT22 cells, an immortalized hippocampal neuronal cell line. We chose to perform the experiments in this cell line because it is well documented that glutathione depletion mediates cellular death in this cell line by affecting the same molecular pathways it does in neurons and because of the ease of transfection methods in cell lines compared with primary neurons. We confirmed HDAC8 protein knockdown (Fig. $5 A$ ) and tested whether HDAC8 knockdown protected against oxidative death. HDAC8 knockdown did not protect HT22 cells from oxidative stress-induced death (Fig. 5B). Moreover, PCI-34051 was able to significantly protect the cells even when HDAC8 levels were reduced, suggesting that PCI-34051's neuroprotective effect is independent from HDAC8 inhibition. To rule out that the neuroprotective effect of PCI-34051 is dependent on its ability to inhibit residual HDAC8 activity in the knockdown cells, we reasoned that, if PCI-34051 mediates neuroprotection by inhibiting residual HDAC8 activity in the HDAC8 knockdown cells, then we would expect to observe that lower doses of PCI-34051 significantly mediate neuroprotection in HDAC8 knockdown cells compared with wild-type cells. Indeed, we did not observe any changes in the PCI-34051 neuroprotective dose-response, suggesting that the compound's neuroprotective effect is independent from inhibition of residual HDAC8 activity (Fig. 5C). To further exclude a role for HDAC8 in oxidative death, we confirmed these results in cortical neurons derived from conditional HDAC8 knock-out mice. We confirmed knockdown in these neurons by real-time RT-PCR (Fig. 5D). Similar to the results obtained in HT22 cells, HDAC8 knockdown in cortical neurons, did not protect against oxidative stress-induced death (Fig. 5E). In addition, both PCI-34051 and BRD3811 continued to protect neurons from oxidative death independent of HDAC8 levels. These results support the conclusion that HDAC8 is not a major player in

A

C
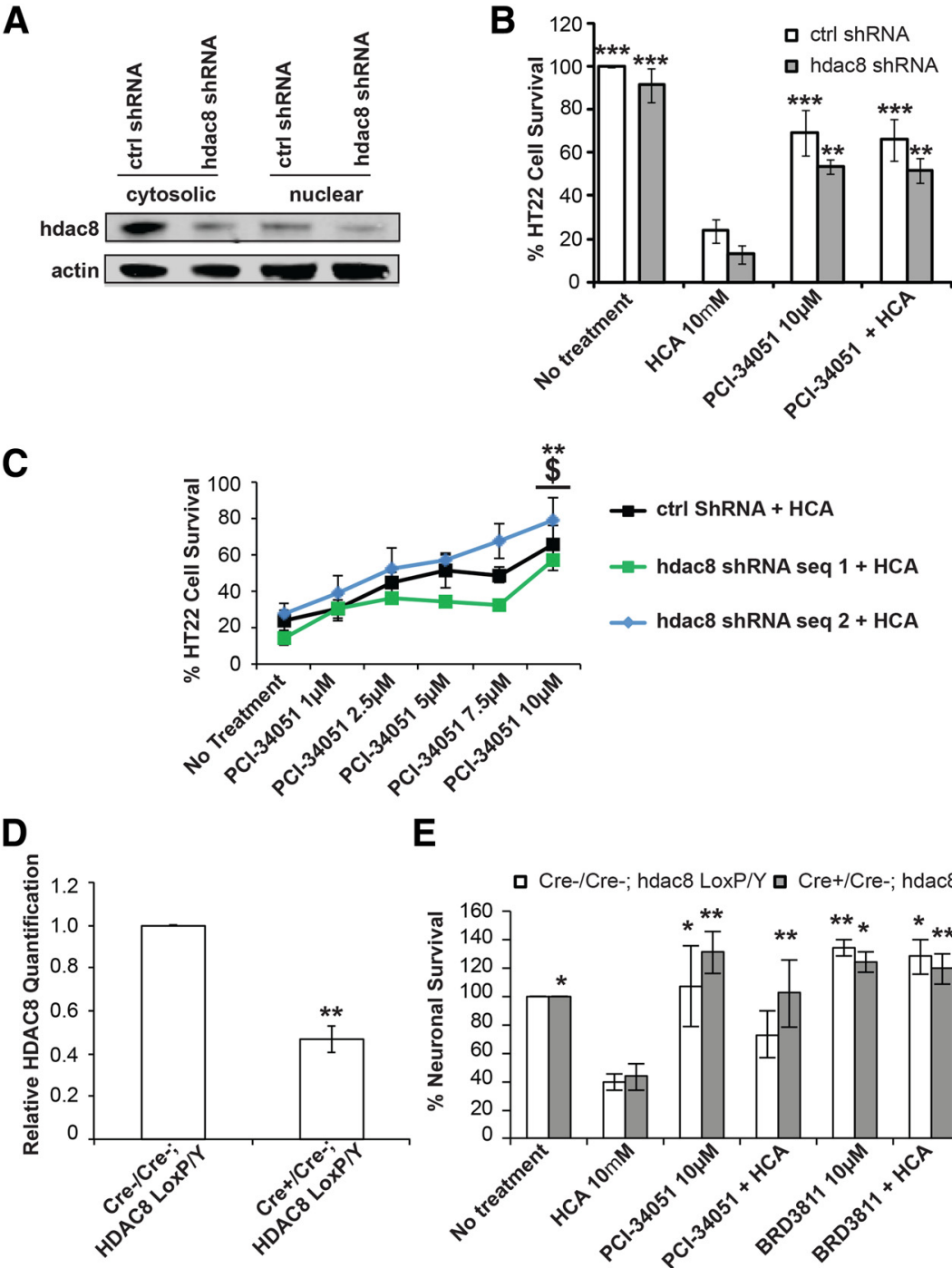

E

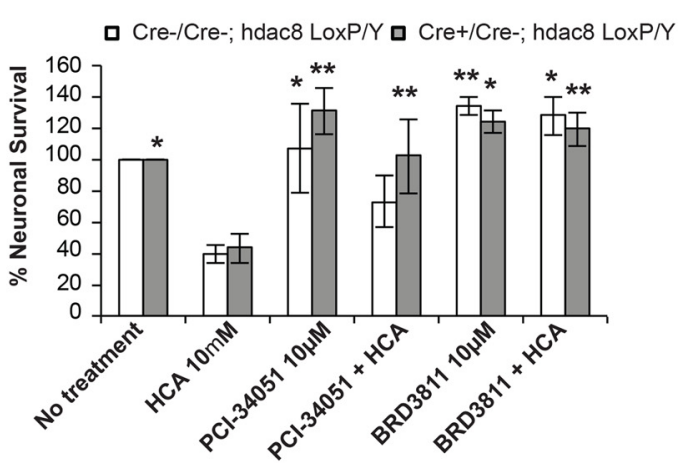

Figure 5. HDAC8 knockdown does not protect cells from glutathione depletion-induced death. $A$, HT22 cells were stably transfected with shRNA against HDAC8, and knockdown was assessed in both the cytosolic and nuclear fractions using Western blots. Indeed, HDAC8 levels were significantly reduced in both cell fractions. $B$, Knockdown of HDAC8 in HT22 cells does not protect against glutathione depletion-induced death. Moreover, $\mathrm{PCl}-34051$ can still significantly protect cells against glutathione depletion-induced neuronal death even when HDAC8 levels were reduced, suggesting that the neuroprotective functions of $\mathrm{PCl}-34051$ are independent of its ability to inhibit HDAC8. Cell death was measured $24 \mathrm{~h}$ after treatment with the glutamate analog HCA with or without $\mathrm{PCl}-34051$ by monitoring MTT reduction. Significant protection compared with HCA-treated cells: ${ }^{* *} p<0.01$; ${ }^{* * *} p<0.0001$. C, The same concentrations of PCl-34051 were required to mediate protection against oxidative death both in Ctrl shRNA and HDAC8 shRNA cells, suggesting that PCl-34051 mediates neuroprotection independent of any inhibition of residual HDAC8 activity. D, Knock-out of HDAC8 in primary cortical neurons was established by real-time RT-PCR. Significant knockdown compared with Cre-/Cre-; HDAC8 LoxP/Y cells: ${ }^{* *} p<0.01$. E, Knock-out of HDAC8 in primary cortical neurons does not protect from glutathione-induced death. Moreover, both PCI-34051 and BRD3811 can still significantly protect cells against glutathione depletion-induced neuronal death, suggesting that the neuroprotective functions of both PCI-34051 and BRD3811 are independent from their ability to inhibit HDAC8. Cell death was measured $24 \mathrm{~h}$ after treatment with the glutamate analog $\mathrm{HCA}$ with or without $\mathrm{PCI}-34051$ or BRD3811 by monitoring MTT reduction. Significant protection compared with HCA-treated cells: ${ }^{*} p<0.05$; ${ }^{* *} p<0.01$.

oxidative stress-induced neuronal death. However, the precise mechanism for protection by PCI-34051 and BRD3811 remained unclear.

\section{PCI-34051 and BRD3811 mediate neuroprotection via their} hydroxamic acid group

When choosing to use BRD3811, we made a conscious decision to preserve the hydroxamic acid moiety of PCI-34051, as we felt that this functional group would be the most likely contributor to any off-target effects (Olson et al., 2014). However, when our 
A
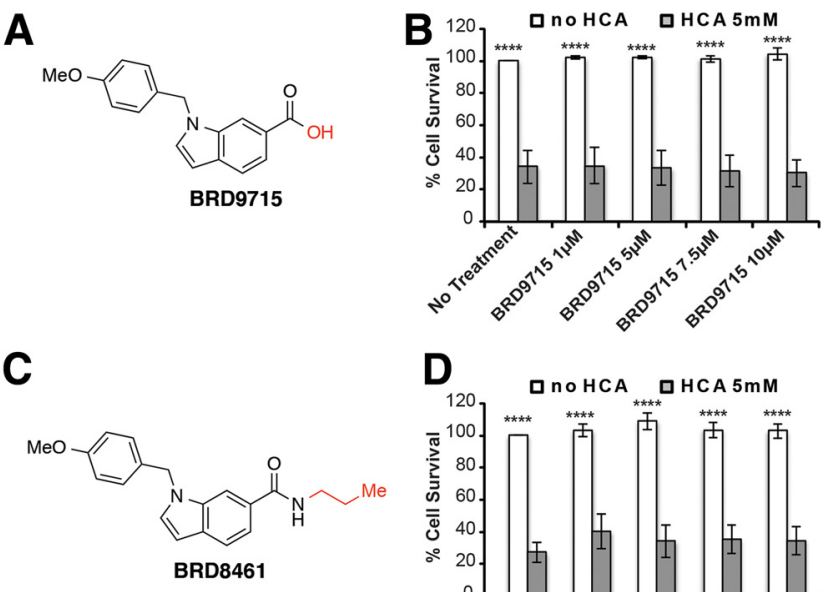

D

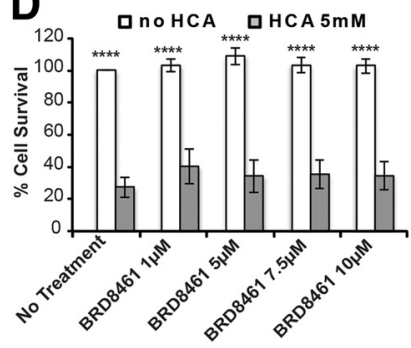

Figure 6. The hydroxamic acid group of $\mathrm{PCl}-34051$ and BRD3811 is necessary for their ability to protect against glutathione depletion-induced neuronal death. $A$, Structure of BRD9715. This compound only differs from $\mathrm{PCl}-34051$ by the conversion of the hydroxamic acid group to an acid group. $B$, BRD9715 does not protect primary cortical neurons from glutathione depletioninduced neuronal death. $\boldsymbol{C}$, Structure of BRD8461. This compound only differs from PCI-34051 by the conversion of the hydroxamic acid group to a propylamide group. D, BRD8461 does not protect primary cortical neurons from glutathione depletion-induced neuronal death. Cell death was measured $24 \mathrm{~h}$ after treatment with the glutamate analog HCA with or without BRD9715 or BRD8461 by monitoring MTT reduction. Significant protection compared with HCAtreated cells: ${ }^{* * * *} p<0.0001$.

studies revealed that neuroprotection mediated by PCI-34051 and BRD3811 was not the result of HDAC8 inhibition, we decided to more thoroughly investigate the role of the hydroxamic acid group. Therefore, we designed and synthesized BRD9715 and BRD8461, two additional orthologs of PCI-34051 in which we replaced the hydroxamic acid moiety with a nonchelating acid (Fig. 6A) or propylamide group (Fig. 6C). We ensured that these two compounds were permeable and stable (data not shown). Not surprisingly, replacement of the hydroxamic chelating moiety with the acid or propylamide groups ablated all HDAC binding activity (Table 1). As anticipated, BRD9715 and BRD8461 failed to protect primary cortical neurons from oxidative death, suggesting that the hydroxamic acid group in PCI-34051 and BRD3811 is indeed critical for neuroprotection (Fig. 6B,D).

\section{Discussion}

Evidence suggests that environmental factors may contribute to neurodegeneration through changes in epigenetic modifications, such as DNA methylation, and histone acetylation. The induction of epigenetic changes is thought to induce alterations in gene expression programs. Epigenetic regulation has garnered significant attention because molecules that regulate epigenetic pathways, such as HDACs, appear to play important roles in disease progression both in in vitro and in vivo models of CNS diseases. Using various methods, several groups have demonstrated that HDACi ameliorate the symptoms of many chronic and acute CNS diseases, including Alzheimer's disease and Huntington's disease and have implicated specific HDAC isoforms in these pathological processes. Indeed, there has been an urgent call to develop isoform-selective HDACi to study the role of individual HDACs and to potentially assess the therapeutic potential of such compounds. Here, we used a selective HDAC8 inhibitor and three distinct inactive structural orthologs to illustrate that a de-

gree of caution is required when interpreting the effects of pharmacological modulators and the roles of their primary biological targets, in this case specific HDAC isoforms. Our results emphasize the importance of careful validation of structure-activity relationship studies when using pharmacological approaches to answer a biological question. We used several isoform-selective HDACi in an attempt to identify the Class I HDAC(s) involved in glutathione depletion-induced neuronal death (Fig. 1; and data not shown). We showed that PCI-34051, a compound that has been widely used as a potent and highly selective HDAC8 inhibitor (Fig. 2), protects murine cortical neurons from oxidative stress. It was only when we used BRD3811 (Fig. 3), a compound derived from PCI-34051, but lacking the latter's ability to inhibit HDAC8, that we discovered that HDAC8 inhibition is not the "on-target" neuroprotective effect of this compound (Fig. 4). We confirmed this finding by showing that HDAC8 knockdown in neurons does not protect against oxidative death (Fig. 5). Finally, we designed and synthesized BRD9715 and BRD8461, two additional structural analogs of PCI-34051 lacking the hydroxamic acid chelating motif and devoid of any HDAC inhibitory activity to show that the mechanism of neuroprotection from oxidative death is dependent on the hydroxamic acid groups of PCI-34051 and BRD3811 (Fig. 6). Our results led us to reassess the data published, especially with respect to hydroxamic acid-containing HDACi.

Even though the role of some HDAC isoforms in CNS diseases has been established through genetic knock-out or knockdown studies, the vast majority of studies have used HDACi to show protective effects in CNS diseases and cancer. Of these studies, a limited number have actually shown that these compounds protect neurons by inhibiting a HDAC or a subset of HDACs and have tested the compounds in genetic knock-outs of specific HDACs. Such studies, though, are complicated, especially when more than one HDAC contributes to the disease or the inhibitor's protective effect. The design of structurally similar, yet pharmacologically inert, compounds could indeed alleviate some of the difficulties of such experiments. Indeed, nullscript, a hydroxamic acid that shares a similar structure to the HDAC inhibitor Scriptaid and that is however unable to inhibit HDACs in the same concentration range as Scriptaid, serves as an ideal negative control to identify the HDAC inhibition "on-target" effects of Scriptaid. By using BRD3811 as a negative control for PCI-34051, we are now poised to identify HDAC 8 target genes in neurons, a finding that has been elusive so far in neurons. Mutations affecting the histone deacetylase domain of HDAC8 have been reported to cause Cornelia de Lange syndrome, a disease characterized by craniofacial abnormalities and mental retardation in children (Deardorff et al., 2012). Identification of HDAC8 target genes in neurons will shed light on the molecular mechanisms underlying this disease.

In addition to identifying HDAC target genes, the development of carefully designed negative control compounds will help identify key functional motifs necessary for neuroprotection. Indeed, by designing compounds in which the hydroxamic acid moiety of PCI-34051 and BRD3811 was converted to an acid or a propylamide group (Fig. 6), we were able to provide evidence that the hydroxamic acid moiety of these compounds is necessary for their neuroprotective effect. The hydroxamic acid moiety can be a promiscuous chemical motif that has been shown to have a strong ability to chelate metals, including iron or zinc outside the context of the HDAC enzyme family. Because the glutathione depletion-induced neuronal death is known to be iron-dependent (Dixon et al., 2012) and because the concentrations at which the HDACi are neuroprotective $(\mu \mathrm{M})$ are more consistent with the cel- 
lular concentration of chelatable iron than their HDAC potencies (nM), we speculate that an alternative mechanism involving iron might be responsible for the neuroprotective properties of these compounds (D.E.O. et al., manuscript in preparation).

In the CNS, iron is important for many cellular processes, including gene expression, DNA synthesis, mitochondrial electron transport, and other metabolic processes. Iron accumulation and deposition play important roles in the progression of neurodegeneration (Weinreb et al., 2010). High concentrations of iron react with hydrogen peroxide in the Haber-Weiss/Fenton reaction to produce hydroxyl radicals and in turn lead to oxidative stress and cellular death (Smith et al., 1997). As such, a wealth of data indicates that molecules capable of chelating iron can mediate neuroprotection (Weinreb et al., 2010). In addition to the induction of oxidative stress, iron plays important roles as a substrate to enzymes, such as the iron-dependent dioxygenases, such as hypoxia inducible factor (HIF)-prolyl-4-hydroxylases (HIF-PHDs) and the Tet proteins. HIF-PHD inhibition by iron chelators, such as deferoxamine, has been shown to be protective against oxidative death (Aminova et al., 2008; Siddiq et al., 2009). Considering that modeling analysis suggested that PCI-34051 and BRD3811 may inhibit HIF-PHDs, we have tested whether these compounds can stabilize HIF $1 \alpha$ and whether they can protect neurons derived from HIF-PHD triple knock-out mice. Our results suggest that the mechanism of protection is independent from HIF-PHD inhibition (S.F.S. and R.R.R., unpublished data). However, it remains a strong possibility that metal chelation either to reduce ROS or to interfere with enzymatic reactions in the ERK/MAPK pathway could be a way by which the hydroxamic acids PCI-34051 and BRD3811 are neuroprotective. One possibility by which these compounds can interfere with ERK phosphorylation is through inhibition of 12-lipoxygenase. Indeed, 12/ 15-lipoxygenases have been implicated in diabetes-induced ERK phosphorylation in the peripheral nerve and dorsal root ganglion neurons (Stavniichuk et al., 2012), and hydroxamic acids through their iron-chelating abilities can act as lipoxygenase inhibitors (Dailey and Imming, 1999). Interestingly, 12-lipoxygenase is a wellestablished mediator of glutathione depletion-induced neuronal death and 12-lipoxygenase inhibitors are neuroprotective (Li et al., 1997). In separate studies, we did not find that PCI-34051 and BRD3811 inhibit recombinant 12-lipoxygenase activity (Sleiman, Holman, and Ratan, unpublished observations).

Together, our findings suggest that hydroxamic acids may mediate neuroprotection at least in part through HDACindependent mechanisms. We speculate that these mechanisms may involve the ability of these molecules to sequester iron (D.E.O. et al., manuscript submitted). Even though our data suggest that some hydroxamic acid HDAC inhibitors protect via a mechanism independent of HDAC inhibition, our prior published data established the importance of inhibiting HDACs for neuroprotection from oxidative stress. Indeed, Scriptaid is a hydroxamic acid HDAC inhibitor that protects against neuronal oxidative death, whereas Nullscript, its negative control ortholog that still retains the hydroxamic acid side chain of Scriptaid but lacks the ability to inhibit HDACs at comparable doses does not protect neurons against oxidative death. This, along with our observation that nonhydroxamic acid HDAC inhibitors, such as Apicidin (Fig. 1) or sodium butyrate (Ryu et al., 2003), protects against neuronal oxidative death suggests that HDACs may still be relevant targets for preventing neuronal death. Our data, however, present the field with an important tale of caution about overinterpreting results obtained with HDACi and make the argument that an interdisciplinary approach emphasizing the close interaction between both chemical design of compounds and biological testing is needed if we are going to interpret accurately the wealth of the data available from pharmacological interventions.

\section{References}

Aminova LR, Siddiq A, Ratan RR (2008) Antioxidants, HIF prolyl hydroxylase inhibitors or short interfering RNAs to BNIP3 or PUMA, can prevent prodeath effects of the transcriptional activator, HIF-1alpha, in a mouse hippocampal neuronal line. Antiox Redox Signal 10:1989-1998. CrossRef Medline

Balasubramanian S, Ramos J, Luo W, Sirisawad M, Verner E, Buggy JJ (2008) A novel histone deacetylase 8 (HDAC8)-specific inhibitor PCI-34051 induces apoptosis in T-cell lymphomas. Leukemia 22:1026-1034. CrossRef Medline

Bardai FH, D’Mello SR (2011) Selective toxicity by HDAC3 in neurons: regulation by Akt and GSK3beta. J Neurosci 31:1746-1751. CrossRef Medline

Bardai FH, Price V, Zaayman M, Wang L, D’Mello SR (2012) Histone deacetylase-1 (HDAC1) is a molecular switch between neuronal survival and death. J Biol Chem 287:35444-35453. CrossRef Medline

Bardai FH, Verma P, Smith C, Rawat V, Wang L, D’Mello SR (2013) Disassociation of histone deacetylase- 3 from normal huntingtin underlies mutant huntingtin neurotoxicity. J Neurosci 33:11833-11838. CrossRef Medline

Bradner JE, West N, Grachan ML, Greenberg EF, Haggarty SJ, Warnow T, Mazitschek R (2010) Chemical phylogenetics of histone deacetylases. Nat Chem Biol 6:238-243. CrossRef Medline

Brochier C, Dennis G, Rivieccio MA, McLaughlin K, Coppola G, Ratan RR, Langley B (2013) Specific acetylation of p53 by HDAC inhibition prevents DNA damage-induced apoptosis in neurons. J Neurosci 33:86218632. CrossRef Medline

Choudhary C, Kumar C, Gnad F, Nielsen ML, Rehman M, Walther TC, Olsen JV, Mann M (2009) Lysine acetylation targets protein complexes and co-regulates major cellular functions. Science 325:834-840. CrossRef Medline

Dailey LA, Imming P (1999) 12-Lipoxygenase: classification, possible therapeutic benefits from inhibition, and inhibitors. Curr Med Chem 6:389398. CrossRef Medline

Deardorff MA, Bando M, Nakato R, Watrin E, Itoh T, Minamino M, Saitoh K, Komata M, Katou Y, Clark D, Cole KE, De Baere E, Decroos C, Di Donato N, Ernst S, Francey LJ, Gyftodimou Y, Hirashima K, Hullings M, Ishikawa $\mathrm{Y}$, et al. (2012) HDAC8 mutations in Cornelia de Lange syndrome affect the cohesin acetylation cycle. Nature 489:313-317. CrossRef Medline

Dixon SJ, Lemberg KM, Lamprecht MR, Skouta R, Zaitsev EM, Gleason CE, Patel DN, Bauer AJ, Cantley AM, Yang WS, Morrison B 3rd, Stockwell BR (2012) Ferroptosis: an iron-dependent form of nonapoptotic cell death. Cell 149:1060-1072. CrossRef Medline

Ferrante RJ, Kubilus JK, Lee J, Ryu H, Beesen A, Zucker B, Smith K, Kowall NW, Ratan RR, Luthi-Carter R, Hersch SM (2003) Histone deacetylase inhibition by sodium butyrate chemotherapy ameliorates the neurodegenerative phenotype in Huntington's disease mice. J Neurosci 23:9418 9427. Medline

Fischer A, Sananbenesi F, Wang X, Dobbin M, Tsai LH (2007) Recovery of learning and memory is associated with chromatin remodelling. Nature 447:178-182. CrossRef Medline

Gaub P, Tedeschi A, Puttagunta R, Nguyen T, Schmandke A, Di Giovanni S (2010) HDAC inhibition promotes neuronal outgrowth and counteracts growth cone collapse through $\mathrm{CBP} / \mathrm{p} 300$ and $\mathrm{P} / \mathrm{CAF}$-dependent p53 acetylation. Cell Death Differ 17:1392-1408. CrossRef Medline

Gräff J, Rei D, Guan JS, Wang WY, Seo J, Hennig KM, Nieland TJ, Fass DM, Kao PF, Kahn M, Su SC, Samiei A, Joseph N, Haggarty SJ, Delalle I, Tsai LH (2012) An epigenetic blockade of cognitive functions in the neurodegenerating brain. Nature 483:222-226. CrossRef Medline

Guan JS, Haggarty SJ, Giacometti E, Dannenberg JH, Joseph N, Gao J, Nieland TJ, Zhou Y, Wang X, Mazitschek R, Bradner JE, DePinho RA, Jaenisch R, Tsai LH (2009) HDAC2 negatively regulates memory formation and synaptic plasticity. Nature 459:55-60. CrossRef Medline

Gui CY, Ngo L, Xu WS, Richon VM, Marks PA (2004) Histone deacetylase (HDAC) inhibitor activation of $\mathrm{p} 21 \mathrm{WAF} 1$ involves changes in promoterassociated proteins, including HDAC1. Proc Natl Acad Sci U S A 101: 1241-1246. CrossRef Medline 
Haberland M, Mokalled MH, Montgomery RL, Olson EN (2009) Epigenetic control of skull morphogenesis by histone deacetylase 8 . Genes Dev 23:1625-1630. CrossRef Medline

Hanson JE, Deng L, Hackos DH, Lo SC, Lauffer BE, Steiner P, Zhou Q (2013) Histone deacetylase 2 cell autonomously suppresses excitatory and enhances inhibitory synaptic function in CA1 pyramidal neurons. J Neurosci 33:5924-5929. CrossRef Medline

Hayashi S, McMahon AP (2002) Efficient recombination in diverse tissues by a tamoxifen-inducible form of Cre: a tool for temporally regulated gene activation/inactivation in the mouse. Dev Biol 244:305-318. CrossRef Medline

Kazantsev AG, Thompson LM (2008) Therapeutic application of histone deacetylase inhibitors for central nervous system disorders. Nat Rev Drug Discov 7:854-868. CrossRef Medline

Kim C, Choi H, Jung ES, Lee W, Oh S, Jeon NL, Mook-Jung I (2012) HDAC6 inhibitor blocks amyloid beta-induced impairment of mitochondrial transport in hippocampal neurons. PLoS One 7:e42983. CrossRef Medline

Kouzarides T (2000) Acetylation: a regulatory modification to rival phosphorylation? EMBO J 19:1176-1179. CrossRef Medline

Lange PS, Chavez JC, Pinto JT, Coppola G, Sun CW, Townes TM, Geschwind DH, Ratan RR (2008) ATF4 is an oxidative stress-inducible, prodeath transcription factor in neurons in vitro and in vivo. J Exp Med 205:12271242. CrossRef Medline

Langley B, D'Annibale MA, Suh K, Ayoub I, Tolhurst A, Bastan B, Yang L, Ko B, Fisher M, Cho S, Beal MF, Ratan RR (2008) Pulse inhibition of histone deacetylases induces complete resistance to oxidative death in cortical neurons without toxicity and reveals a role for cytoplasmic p21(waf1/ cip1) in cell cycle-independent neuroprotection. J Neurosci 28:163-176. CrossRef Medline

Li Y, Maher P, Schubert D (1997) A role for 12-lipoxygenase in nerve cell death caused by glutathione depletion. Neuron 19:453-463. CrossRef Medline

Morris MJ, Mahgoub M, Na ES, Pranav H, Monteggia LM (2013) Loss of histone deacetylase 2 improves working memory and accelerates extinction learning. J Neurosci 33:6401-6411. CrossRef Medline

Mosmann T (1983) Rapid colorimetric assay for cellular growth and survival: application to proliferation and cytotoxicity assays. J Immunol Methods 65:55-63. CrossRef Medline

Oehme I, Deubzer HE, Wegener D, Pickert D, Linke JP, Hero B, KoppSchneider A, Westermann F, Ulrich SM, von Deimling A, Fischer M, Witt O (2009) Histone deacetylase 8 in neuroblastoma tumorigenesis. Clin Cancer Res 15:91-99. CrossRef Medline

Olson DE, et al. (2014) An unbiased approach to identify endogenous substrates of "histone" deacetylase 8. ACS Chem Biol. Advance online publication. Retrieved Aug. 11, 2014. doi: 10.1021/cb500492r. CrossRef Medline
Ratan RR, Murphy TH, Baraban JM (1994a) Macromolecular synthesis inhibitors prevent oxidative stress-induced apoptosis in embryonic cortical neurons by shunting cysteine from protein synthesis to glutathione. J Neurosci 14:4385-4392. Medline

Ratan RR, Murphy TH, Baraban JM (1994b) Oxidative stress induces apoptosis in embryonic cortical neurons. J Neurochem 62:376-379. CrossRef Medline

Rivieccio MA, Brochier C, Willis DE, Walker BA, D'Annibale MA, McLaughlin K, Siddiq A, Kozikowski AP, Jaffrey SR, Twiss JL, Ratan RR, Langley B (2009) HDAC6 is a target for protection and regeneration following injury in the nervous system. Proc Natl Acad Sci U S A 106:19599-19604. CrossRef Medline

Ryu H, Lee J, Olofsson BA, Mwidau A, Dedeoglu A, Escudero M, Flemington E, Azizkhan-Clifford J, Ferrante RJ, Ratan RR (2003) Histone deacetylase inhibitors prevent oxidative neuronal death independent of expanded polyglutamine repeats via an Sp1-dependent pathway. Proc Natl Acad Sci U S A 100:4281-4286. CrossRef Medline

Siddiq A, Aminova LR, Troy CM, Suh K, Messer Z, Semenza GL, Ratan RR (2009) Selective inhibition of hypoxia-inducible factor (HIF) prolylhydroxylase 1 mediates neuroprotection against normoxic oxidative death via HIF- and CREB-independent pathways. J Neurosci 29:8828 8838. CrossRef Medline

Sleiman SF, Basso M, Mahishi L, Kozikowski AP, Donohoe ME, Langley B, Ratan RR (2009) Putting the 'HAT' back on survival signalling: the promises and challenges of HDAC inhibition in the treatment of neurological conditions. Exp Opin Invest Drugs 18:573-584. CrossRef Medline

Sleiman SF, Berlin J, Basso M, Karuppagounder SS, Rohr J, Ratan RR (2011) Histone deacetylase inhibitors and mithramycin A impact a similar neuroprotective pathway at a crossroad between cancer and neurodegeneration. Pharmaceuticals 4:1183-1195. CrossRef Medline

Smith MA, Harris PL, Sayre LM, Perry G (1997) Iron accumulation in Alzheimer disease is a source of redox-generated free radicals. Proc Natl Acad Sci U S A 94:9866-9868. CrossRef Medline

Stavniichuk R, Shevalye H, Hirooka H, Nadler JL, Obrosova IG (2012) Interplay of sorbitol pathway of glucose metabolism, 12/15-lipoxygenase, and mitogen-activated protein kinases in the pathogenesis of diabetic peripheral neuropathy. Biochem Pharmacol 83:932-940. CrossRef Medline

Sudo H, Baas PW (2010) Acetylation of microtubules influences their sensitivity to severing by katanin in neurons and fibroblasts. J Neurosci 30 : 7215-7226. CrossRef Medline

Weinreb O, Amit T, Mandel S, Kupershmidt L, Youdim MB (2010) Neuroprotective multifunctional iron chelators: from redox-sensitive process to novel therapeutic opportunities. Antiox Redox Signal 13:919-949. CrossRef Medline 